\title{
Joint Statement by the Gynecologic Radiology Study Group (AGR), the German Society for Gynecology and Obstetrics (DGGG), the German Society for Senology (DGS) and the Professional Association of Gynecologists (BVF)
}

Gemeinsame Stellungnahme der Arbeitsgemeinschaft für gynäkologische Radiologie (AGR), der Deutschen Gesellschaft für Gynäkologie und Geburtshilfe e. V. (DGGG), der Deutschen Gesellschaft für Senologie e. V. (DGS) und des Berufsverbands der Frauenärzte e. V. (BVF)

Authors

Affiliations
H. Junkermann ${ }^{1}$, D. Wallwiener ${ }^{2}$, R. Schulz-Wendtland ${ }^{3}$, C. Albring ${ }^{4}$

1 Member of the board of the AGR

${ }^{2}$ President of the DGGC

${ }^{3}$ President of the DGS

${ }^{4}$ President of the BVF
Deutschsprachige Zusatzinformationen online abrufbar unter: www.thieme-connect.de/ ejournals/toc/gebfra
Bibliography

DOI http://dx.doi.org/

10.1055/s-0034-1383399

Geburtsh Frauenheilk 2014; 74: 1088-1089 ๑ Georg Thieme Verlag KG Stuttgart · New York . ISSN 0016-5751

\section{Correspondence}

Dr. med. Hans Junkermann

Senologische Diagnostik

Universitätsfrauenklinik

Im Neuenheimer Feld 440

69120 Heidelberg

hans.junkermann@

med.uni-heidelberg.de

\section{Recent Findings on Mammography Screening - Scientific Appraisal}

The criticisms directed against mammography screening in recent months have greatly unsettled the potential participants in screening programs. Supposedly, mammography screening would not achieve the reduction in mortality rates expected by seven randomized studies carried out more than 20 years ago. The execution of the studies and their evaluation would have been partially flawed. One of these studies, the randomized Canadian study (CNBSS) which found no reduction in breast cancer mortality rates, was cited as evidence for this. Moreover, it was posited that the improved prognosis resulting from the current use of adjuvant medication meant that early detection using mammography was unlikely to lead to significant decreases in breast cancer mortality.

However, an analysis of the Canadian mammography screening program published a few weeks ago [1], a program which was introduced despite the negative findings of the above-mentioned CNBSS study, underscores the continued efficacy of mammography screening even in current times. A reduction of breast cancer mortality rates by $40 \%$ was reported for women who had undergone mammography screening between 1990 and 2009. These new findings from Canada confirm the assessment that early detection through screening can lead to a significant reduction in breast cancer mortality rates, even when patients receive hormone therapy and chemotherapy in accordance with current standards of care. The results of this recent study support the findings of two analyses of the existing scientific evidence carried out independently from each other at the request of the British government [2] and the Dutch government [3]. Both commissions of experts recommended continuing with the respective national mammography screening programs and developing them further. Women who undergo mammography screening in Germany can also assume that the mortality rates for breast cancer are significantly reduced with screening. Initial analysis has demonstrated the expected decrease in the numbers of advanced stage cancers.

At the request of the German Federal Joint Committee (G-BA) of Physicians and Insurance Companies, the Institute for Quality and Efficiency in Healthcare (IQWiG) is currently revising the information leaflet appended to the invitation to attend screening, so as to allow all women in Germany an independent and well-informed assessment which will weigh the individual benefits against the potential risks of screening based on the most recent scientific knowledge.

After a committee of experts appointed by the WHO rejected the criticisms of the randomized mammography screening studies, the German Bundestag decided in 2002 to introduce a quality-assured mammography screening program in Germany as well. The recent results from Canada confirm this decision. Participation in the German population based, quality-assured mammography screening can still be recommended to all eligible women.

For the Board of the AGR

Dr. Hans Junkermann

Heidelberg, November 17, 2014

For the Board of the DGGG

Prof. Diethelm Wallwiener

Tübingen, November 17, 2014

For the Board of the DGS

Prof. Rüdiger Schulz-Wendtland

Erlangen, November 17, 2014

For the Board of the BVF

Dr. Christian Albring

Hannover, November 17, 2014 


\section{References}

1 Coldman A, Phillips N, Wilson C et al. Pan-Canadian study of mammography screening and mortality from breast cancer. J Natl Cancer Inst 2014; 106: pii: dju261

2 Marmot MG, Altman DG, Cameron DA et al. The benefits and harms of breast cancer screening: an independent review. Br J Cancer 2013; 108: $2205-2240$

3 Health Council of the Netherlands. Population screening for breast cancer: expectations and developments. The Hague: Health Council of the Netherlands; 2014 